\title{
CONEXÕES GEOGRÁFICAS E SEGREGAÇÃo SOCIOESPACIAL PELO USO DAS PRISÕES NO ESTADO DE SÃO PAULO
}

\author{
James Humberto Zomighani Jr.*
}

Resumo: A expansão do sistema penitenciário paulista tem ocorrido cada vez mais pelo uso do território de municípios do interior do estado, distantes das grandes concentrações urbanas e das regiões com maior criminalidade. Essa característica da segregação socioespacial - pela expansão do sistema penitenciário paulista - é parte da estratégia do governo estadual para isolar parcelas da massa carcerária em territórios em que a população tenha menos resistência à instalação de novas prisões, entre outros interesses políticos e econômicos. Entretanto, em decorrência das novas características do meio geográfico, cujo conteúdo é cada vez mais denso em ciência, técnica e informação, surgem novas formas de conexão geográfica entre lugares remotos e possibilidades de se superarem distâncias e romper o isolamento físico. Assim, além do fracasso da pena privativa de liberdade, o fato de os presos também usarem tecnologias de comunicação avançadas - como telefones celulares - implica acelerada ressignificação dos sentidos e das funções da prisão na contemporaneidade. Como antiga concepção arquitetural para isolamento dos condenados, as prisões hoje revelam novos e específicos usos do território pelo sistema de justiça criminal brasileiro, demonstrando como as escalas geográficas e as distâncias são também ressignificadas pelas conexões geográficas.

Palavras-chave: segregação socioespacial, conexões geográficas, sistema penitenciário paulista, período tecnológico, desigualdades socioespaciais.

\section{GEOGRAPHIC CONNECTIONS AND PRISONS USED FOR SOCIOSPATIAL SEGREGATION IN SÃO PAULO STATE}

\begin{abstract}
This paper addresses the discussion that the issue is gaining in small towns Brazilian The expansion of the São Paulo prison system has been, increasingly, using the territory of the municipalities located in country, far from big urban areas and regions with higher statistics of crime. This characteristic of segregation by the expansion of the prison system stems from the state government's strategies in an attempt to isolate the prisoners in areas that have less resistance to the installation of new prisons. However, due to new possibilities of geographical environment, which has contents with increasing densities of science, technology and information, there are new forms of connection between remote places, breaking with the distances. Thus, the use of advanced communication technologies for the prisoners involved in new meanings of prison, isolation and ancient architecture of the damned, since the geographic ranges and the distances are re-signified by these contemporary geographical connections.
\end{abstract}

Keywords: segregation sociospatial, geographic connections, state prisons of São Paulo, technological period, social inequalities.

\section{Introdução}

As Fotos 1 e 2 ilustram novos conteúdos do meio geográfico, que se transforma cada vez mais ao adquirir maiores densidades de ciência, técnica e informação (SANTOS, 2002; 2008). Como atributos que modificam as relações humanas, os novos conteúdos do espaço geográfico (presentes nos usos do território contemporâneo) possibilitam diversificar as formas de ação do poder político e econômico - do Estado e das empresas - sobre os homens e o planeta.

* Doutorando em Geografia Humana pela Faculdade de Filosofia, Letras e Ciências Humanas da Universidade de São Paulo. E-mail: zomigjh@gmail.com. 
Foto 1 - Satélite do sistema GPS em órbita terrestre

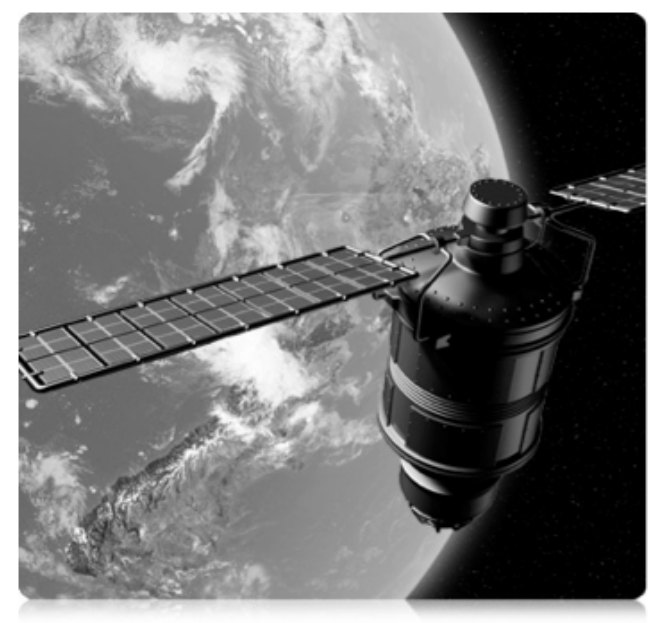

Foto 2 - Homem portando tornozeleira para monitoramento remoto por GPS

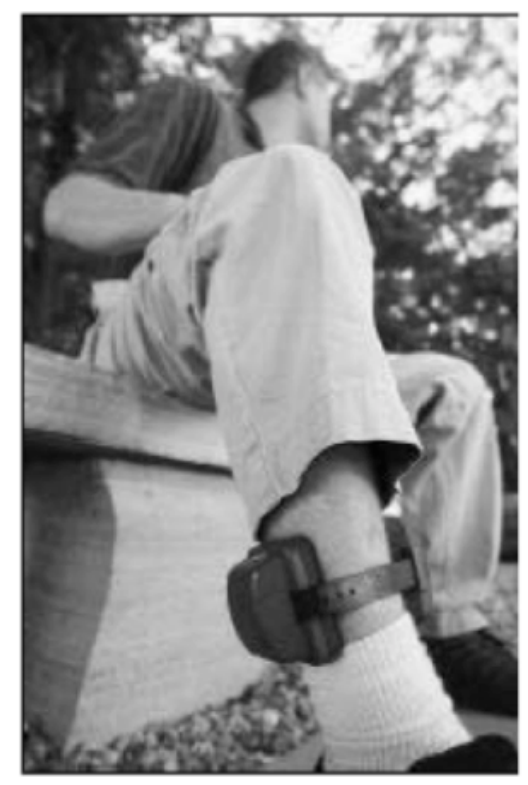

Essa aceleração da história pelo desenvolvimento da tecnologia, muito mais do que servir ao avanço da democracia, tem se mostrado ligada à consolidação da dromocracia, ${ }^{1}$ em que a guerra (em todas as suas faces) é o imperativo maior das escolhas políticas nesses tempos de modernidade (TRIVINHO, 2005).

\footnotetext{
1 "Dromos, prefixo grego que significa rapidez, vincula-se, obviamente - a partir da dimensão temporal da existência -, ao território geográfico (na qualidade de coordenada espacial), portanto à urbis. Mantém, não obstante - algo menos notado - umbilicais ligações com interesses de logística, estratégia e tática, numa palavra, com o campo bélico" (TRIVINHO, 2005, p. 63).
}

A velocidade na expansão, uso e modernização dos sistemas técnicos - que hoje são adotados intensamente pelo sistema de justiça criminal - processo que possui agentes e interesses difíceis de serem identificados, configura essa condição transpolítica que implica novos movimentos no mundo contemporâneo (TRIVINHO, 2006).

É por isso que o desenvolvimento e uso de novas e modernas tecnologias tem modificado intensamente os usos do território e, como consequência, o funcionamento de várias sociedades do mundo contemporâneo. O monitoramento remoto de prisioneiros, através de satélites do Sistema GPS, e o uso de telefones celulares - que permitem a comunicação entre regiões distantes e não contíguas, são algumas das práticas sociais que têm alterado a organização e o funcionamento do Sistema de Justiça Criminal-SJC de um país como o Brasil, ou seja, dos conjuntos formados por seus sistemas policial, penitenciário e judiciário.

Ao considerar esses fundamentos do mundo contemporâneo, um dos objetivos deste artigo será demonstrar como algumas das novas possibilidades do período tecnológico (SANTOS, 2008) reorganizam e rearticulam escalas geográficas não contíguas. Outro será apresentar resultados de uma pesquisa inédita na geografia sobre os usos do território pelo sistema penitenciário paulista (SPP), principalmente de aspectos que demonstram equívocos na atual política de expansão penitenciária, e que tem ocorrido nos últimos anos no território do estado de São Paulo.

São Paulo possui o maior sistema penitenciário do Brasil, com quase 200 mil 
prisioneiros, e cerca de 150 penitenciárias, e é um dos sistemas prisionais estaduais que mais cresce no país. Este crescimento significa aumento de gastos, dificuldades em sua gestão e diversas outras consequências, em várias escalas, para a sociedade e governo paulistas.

A expansão territorial do SPP em direção a pequenos municípios do interior do estado expressa uma dialética entre a concentração espacial do crime e a localização das novas prisões, pois esses dois elementos ocupam posições opostas no território paulista. Por isso ocorre uma esquizofrenia espacial (SANTOS, 2000) no deslocamento da prisão para regiões distantes das áreas de maior criminalidade, e dos locais de origem de parte significativa dos prisioneiros.

Qual a lógica do deslocamento espacial das prisões para o interior do estado de São Paulo? Como hipótese principal, há um uso do território pela prisão como estratégia para isolamento dos condenados, e tentativa de segregação mais eficaz de lideranças das organizações criminosas que atuam dentro e fora das prisões. ${ }^{2}$ Assim, o governo paulista busca isolar uma parte importante da massa carcerária dos grandes centros urbanos, locais de origem da maioria

\footnotetext{
2 Em 26 de março de 2001, foi firmado um contrato entre a Secretaria de Administração Penitenciária do estado de São Paulo e a empresa Cobel Construtora de Obras e Engenharia Ltda. para a construção do Centro de Readaptação Penitenciária de Presidente Bernardes, município a cerca de $580 \mathrm{~km}$ de São Paulo (capital). Foi a primeira penitenciária do país a adotar o Regime Disciplinar Diferenciado (RDD), criado para isolar lideranças prisionais, sobretudo como resposta à megarebelião com comando unificado ocorrida em 8 de fevereiro de 2001 em diversas unidades prisionais paulistas (Fonte: Tribunal de Contas do Estado de São Paulo. Processo $\mathrm{n}$. 13.752/026/2001).
}

dos presos, e meio geográfico com o qual possuem maiores articulações.

Como explicações secundárias, há diversas outras questões como pactos políticos com prefeitos locais, interesses econômicos (construtoras, incorporadores imobiliários), somados às resistências e aos custos da instalação de novas prisões em municípios maiores, localizados nas regiões de maior concentração urbana do estado de São Paulo (como as regiões de Campinas, São Paulo e Santos, por exemplo).

Além desses elementos, neste artigo também serão discutidos os significados do isolamento prisional diante das possibilidades de conexão entre lugares distantes, dadas as características do atual período tecnológico. $\mathrm{Na}$ análise deste processo foram estudadas algumas das contradições técnicas e políticas envolvendo a expansão territorial do SPP, como tentativa de isolar os presos do mundo exterior à prisão, processo que nem sempre alcança êxito dadas as dinâmicas inerentes tanto ao universo prisional paulista, quanto às novas características do espaço geográfico contemporâneo, como será visto.

\section{Fundamentos teórico-metodológicos da pesquisa}

A estrutura e os conteúdos do meio geográfico passam por mudanças intensas em decorrência dos "novos" movimentos da história, por conta da modernização do território dos países, e do aporte de eventos originários de processos que trazem outras possibilidades de ação às sociedades contemporâneas. Por isso o surgimento de novas e importantes formas de conexão geográfica, na lenta passagem do meio 
natural ao meio técnico-científico-informacional, processo que durou vários séculos (SANTOS, 1998).

O espaço geográfico, de um conjunto isolado de lugares, passa a uma totalidade dinâmica por conta da unicidade técnica (SANTOS, 2002) que permite a convergência dos momentos e que a história passe a ter um motor único (SANTOS, 2000). Estas características, resultantes das mudanças do espaço geográfico mundial por conta dos avanços tecnológicos, revelam novas possibilidades de convergência e integração pela técnica e pela política- entre lugares remotos, em todas as escalas do território de um país.

O avanço dos sistemas de transportes e comunicações tem alterado o modo como ocorrem as conexões entre os lugares. À medida que chegam as modernizações desses sistemas, são também modificadas as possibilidades de conexão com o restante do mundo. A face aparente deste processo têm sido o aumento dos fluxos (matérias, mercadorias, informações, pessoas) a partir de fins do século XVIII. ${ }^{3}$ Para um autor como Santos (1997, p. 201), este é o processo que configura verticalidades que, juntamente com as horizontalidades, são formas de conexão e reconfiguração do espaço geográfico nesta contemporaneidade, modificando o formato, a natureza e o conteúdo dos lugares e regiões.

No passado - principalmente até fins do século $X I X$ e começo do século $X X$, havia

\footnotetext{
3 "A relação humana com a dimensão dromológica da existência está ligada à descoberta (recorrente e aglomerativa, sem ser necessariamente complanada e, sobretudo, linear e/ou progressiva), de vetores de movimentação geográfica de corpos, objetos e valores (materiais e simbólicos)" (TRIVINHO, 2005, p. 66).
}

um imperativo das escalas "menores" se articularem com escalas intermediárias para que pudessem se conectar com outras maiores, mais distantes e mais complexas. No caso da chamada "rede urbana", por exemplo, uma vila (escala menos abrangente), dependia da cidade regional para se conectar com o restante do país ou do mundo. No caso, porquê o menor era, na maior parte das vezes, mais simples do que territórios mais abrangentes e, portanto, mais complexos.

No atual período, o lugar menos abrangente - em área - pode também abrigar a complexidade do mundo, se for "nó" das redes e dos sistemas técnicos, por exemplo. Condição exigente da presença do meio técnico, científico e informacional MTCINF, o novo meio geográfico que se expande após a Segunda Guerra Mundial, mas que se consolida, principalmente, a partir dos anos de 1970 (SANTOS, 2002). ${ }^{4}$

As novas possibilidades do MTCINF permitem que o lugar mais simples e remoto também tenha possibilidades de se conectar diretamente com outros lugares distantes e mais complexos, devido aos avanços dos meios de comunicação e transportes.

"A invenção do telefone, do rádio, da TV, da internet, no campo das comunicações e, no dos transportes, do motor a explosão e todas as formas de aplicação dessa nova tecnologia (navios, carros e caminhões, aviões convencionais e a jato) alterou as dinâmicas da circulação de ordens, pessoas e produtos no mundo contemporâneo. É por

\footnotetext{
4 "La troisième période commence pratiquement après la deuxième guerre mondiale, mais son affirmation, qui s'étend aux pays du Tiers Monde, ne se fait qu'à partir des années 1970" (SANTOS, 1997, p. 169).
} 
isso que o período atual é aquele da aceleração contemporânea" (SANTOS, 2002), e ensejou mudanças irreversíveis no funcionamento das sociedades atuais, na busca da eficácia sócio-técnica histórica. ${ }^{5}$

Essas mudanças do meio geográfico promoveram alteração das relações socioespaciais em diversas escalas - do lugar à região. Assim, as antigas contiguidades, fundamentos de formação e consolidação de uma região, por exemplo, foram alteradas pelas possibilidades de conexão direta lugar-mundo, sem a necessidade de intermediários (SOUZA, 1991).

Assim, os lugares, que formam-se a partir do mundo e contêm a sua essência, podem agora interferir diretamente no funcionamento global, apesar do funcionamento das redes promover uma ordem mundial e, muitas vezes, desordem local (SANTOS, 1997, p. 197).

Entretanto, apesar das novas características do mundo terem renovado as dinâmicas espaciais e a relação entre lugares, há ainda formas de gestão e organização de instituições que desconsideram esse movimento do espaço contemporâneo - como pode-se perceber pelas formas de planejamento e gestão do SJC.

O sistema penitenciário - um dos componentes do SJC - é uma dessas instituições que se modifica pela presença do MTCINF, mas que ainda tem sido planejado a partir de fundamentos de realidades já ultrapassadas. A ideia de isolamento - pela

\footnotetext{
5 "A alta lentidão do desempenho motriz corporal, sobremaneira agrilhoado ao solo, o futuro dromocrático acenaria, obviamente, com uma dissolução fatal e irreversível, mediante a chegada de vetores cada vez mais eficazes" (TRIVINHO, 2005, p. 66).
}

distância, pelo banimento, pela arquitetura tem se transformado por conta das novas possibilidades do MTCINF.

Deste modo, hoje, a prisão mais longínqua tem a possibilidade de estar conectada a outros lugares remotos, e com eles interagir (pela troca de informações, ordens, produtos, normas), ${ }^{6}$ e pelas demandas que gera ao se instalar, por exemplo, em um município com baixa oferta local ou regional de produtos e serviços. ${ }^{7}$

É por isso que pode-se considerar que o funcionamento do Sistema de Justiça Criminal - SJC participa de escalas que não são contidas por alguns dos limites político-administrativos hoje existentes no país (como os limites do município, ou das próprias unidades da federação). Esta condição é exigente de outra concepção, uso e planejamento do próprio sistema penitenciário, a partir da consideração da articulação - pela técnica - entre as escalas geográficas não contíguas.

Uma das análises feitas no curso desta pesquisa considera algumas dessas contradições que envolvem o funcionamento territorial do Sistema de Justiça Criminal Paulista. Como instrumental técnico para

\footnotetext{
6 "Em conjunção ao largo expediente histórico de deslocamento geográfico de bens materiais, desencadeia-se pois, embaralhando os fatores inplicados, a era do deslocamento mediático de bens imateriais. Os vetores de produção de movimento convencional cedem espaço aos de transmissão e circulação de produtos simbólicos (informações e imagens), representativos ou não de referentes concretos" (TRIVINHO, 2005, p. 66).

7 No caso das prisões francesas, um autor como Marchetti (1996, p. 45) demonstra com propriedade como o comércio local em municípios pequenos não se beneficia da instalação de uma prisão, pois, em geral. as compras para abastecer a prisão são feitas no atacado, respeitando regras rígidas, muitas vezes criadas para atender a um conjunto de prisões de diferentes lugares ou definidas em outras escalas de governo, para além do governo local.
} 
representação dos dados empíricos, utilizouse a informática e a cartografia digital para criação de mapas temáticos, ${ }^{8}$ bem como o trabalho com dados estatísticos obtidos em diversas fontes, ${ }^{9}$ como veremos.

\section{Conexões geográficas e difusão da informação}

As redes técnicas - que possibilitam conexão entre lugares remotos - permitem a circulação de ordens, idéias e informações sem necessidade de escalas intermediárias. Através do uso das redes emergem as conexões geográficas (SOUZA, 1991) que tornam possível a articulação lugar-mundo, rompendo-se com as distâncias que impunham limites estruturais aos intercâmbios diretos e à comunicação sem intermediários.

A própria informação é a energia principal para o funcionamento dos objetos técnicos no MTCINF (SANTOS, 1997, p. 169).

Por conta do uso de novas tecnologias, disponíveis em formatos como os da Internet, das comunicações via satélite e da telefonia celular (também conhecidas como tecnologias da informação e comunicação - TIC), têm sido criadas as bases de um mundo novo. A globalização é talvez uma das maiores resultantes desse

\footnotetext{
${ }^{8}$ O software utilizado foi o MAP INFO versão 6.0 , uma ferramenta para montagem de sistemas de informações georeferenciadas (SIG), fundamental para análises territoriais, e o método estatístico cartográfico foi o de "quebras naturais", importante para a lida com grande quantidade de dados, como o caso do estado de SP.

9 Fundação Seade e Secretaria de Administração Penitenciária do Estado de São Paulo, bem como diversas fontes jornalísticas e sites de empresas de informática e telecomunicações.
}

processo, ${ }^{10}$ pois as redes permitem dispersão da produção, e a centralização de seu comando nos países centrais do sistema político-econômico atual (SANTOS 1998).

É também o processo previsto por Marx e comprovado por autores como Santos (1997) quando falam de diminuição da arena e aumento da área de ação dos agentes do atual sistema político-econômico hegemônico mundial.

As TICs foram criadas para atender diversas necessidades, tanto civis quanto militares. ${ }^{11}$ Desde sua invenção, passaram a ser difundidas, de maneira acelerada, pelos territórios de diversos países, como consequência das modernizações que a eles chegam. Parte desse processo é comandada por empresas transnacionais, na busca da ampliação de mercados para seus produtos e serviços, ${ }^{12}$ inclusive junto às camadas mais pobres da população. ${ }^{13}$

10 "As tecnologias da informação e comunicação (TIC) são entendidas como o conjunto convergente de tecnologias em microeletrônica, computação (máquinas e programas) e telecomunicações. O Brasil vive atualmente um grande momento de expansão no uso e vendas de produtos e serviços dessas tecnologias. A título de exemplo, foram registrados no ano de 2007 um forte crescimento na venda de computadores e um número recorde no cálculo do ingresso de clientes no mercado de telefonia móvel. No mesmo período, o acesso residencial a Internet aumentou 50\%, chegando a 21,1 milhões de usuários de acordo com dados divulgados pelo Ibope/NetRatings. No mundo, 0 número de internautas chegou a 824.435 milhões em janeiro último, com um crescimento de 10,4\% em relação ao ano passado. Na América Latina, o crescimento foi de 16,6\%" (Disponível em: <http://www.brasilwiki.com.br/>. Acesso em: 7 fev. 2009).

11 "De fato, a história do domínio da velocidade está imanentemente atrelada à história das técnicas e tecnologias de realização da guerra" (TRIVINHO, 2005, p. 67).

12 A produção de aparelhos celulares organiza-se de forma bastante concentrada, pois apenas seis empresas produziram cerca de $84 \%$ dos telefones celulares, de um total de 303 milhões, aproximadamente, fabricados somente no terceiro trimestre de 2008. São elas: Nokia, Samsung, 
Incorporadas ao território dos países, essas modernizações podem alterar substancialmente a realidade dos indivíduos, empresas, instituições e lugares, por modificar as possibilidades de comunicação entre eles, dentre outras mudanças que provocam no funcionamento das sociedades locais e nacionais.

Mesmo os municípios mais distantes, abrigando vetores das TICs, conseguem se conectar diretamente com o mundo. Desse modo, o conjunto de instituições que fazem parte da organização da sociedade e do Estado passa a experimentar mudanças, sendo o isolamento das capitais ou grandes centros urbanos, agora, uma condição que pertence apenas ao passado desses lugares.

\section{Usos do território e segregação socioespacial}

A maioria dos indivíduos cumprindo pena nas penitenciárias paulistas origina-se na capital (município de São Paulo), na Região Metropolitana de São Paulo - RMSP ou em outras regiões populosas como a Região Metropolitana de Campinas. Esta parece ser mais uma das contradições da metrópole corporativa e fragmentada (SANTOS, 1990), já que as novas unidades prisionais têm sido construídas na região Oeste (ZOMIGHANI JR., 2009), ou seja, localizadas a centenas de

Sony Ericsson, Motorola, LG Eletronics e Apple. Outros fabricantes detinham apenas $16 \%$ do mercado mundial de aparelhos celulares naquele ano (http://applemania.info/; acesso em: $6 \mathrm{fev}$. 2008).

13 "Empresários e operadoras asseguram que com impostos menores, as tarifas poderiam ser bem mais atraentes e competitivas, o que propiciaria uma expansão dos serviços e consequentemente o aumento da penetração da telefonia fixa nas camadas mais baixas do país, a única faixa com potencial de crescimento, já que as classes A e B têm um índice de adesão ao serviço de praticamente 100\%" (Disponível em: <http://www.administradores.com.br/noticias>. Acesso em: 7 fev. 2009). quilômetros e muitas horas de distância das regiões mais populosas do Estado de São Paulo.

Há atualmente poucos dados sobre a mobilidade dos presos no território paulista. A carência de estudos teóricos e empíricos sobre os prisioneiros no Brasil corrobora a tese de que eles são mesmo, como aponta Michele Perrot, os excluídos da história (PERROT, 2006). Num dos poucos estudos empíricos disponíveis para o estado de São Paulo, o Censo Penitenciário de 2002 revela que uma parte significativa dos presos paulistas originou-se na capital $(36,4 \%)$ e na Grande São Paulo (13,9\%) (Gráfico 1).

Quanto aos municípios que estão recebendo as novas unidades prisionais paulistas, a maioria se localiza a centenas de quilômetros do município de São Paulo (capital).

Como a população concentra-se nas grandes regiões, distantes desses municípios (Mapa 1), pode-se perguntar que lógica orienta o deslocamento das novas unidades prisionais (principalmente das penitenciárias, unidades para presos condenados) para o interior do estado, em municípios muito distantes da capital (Tabela 1).

Gráfico 1 - Estado de São Paulo. Origem dos presos em $2002(\mathrm{em} \%)^{14}$

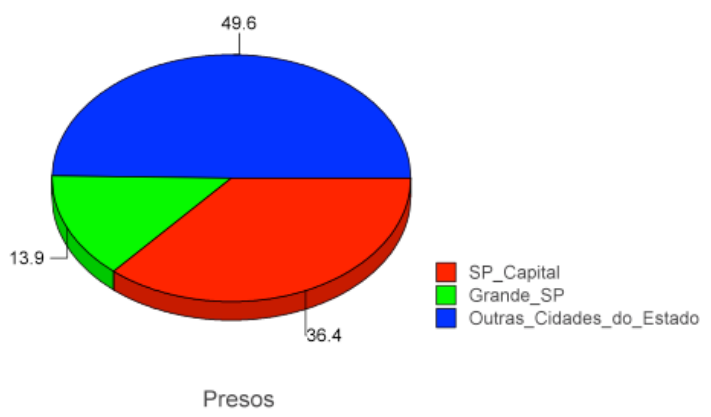

${ }^{14}$ Censo Penitenciário. Secretaria de Administração Penitenciária do Estado de São Paulo, 2002. 
Mapa 1 O ESTADO DE SÃO PAULO - População por Município em 2007.

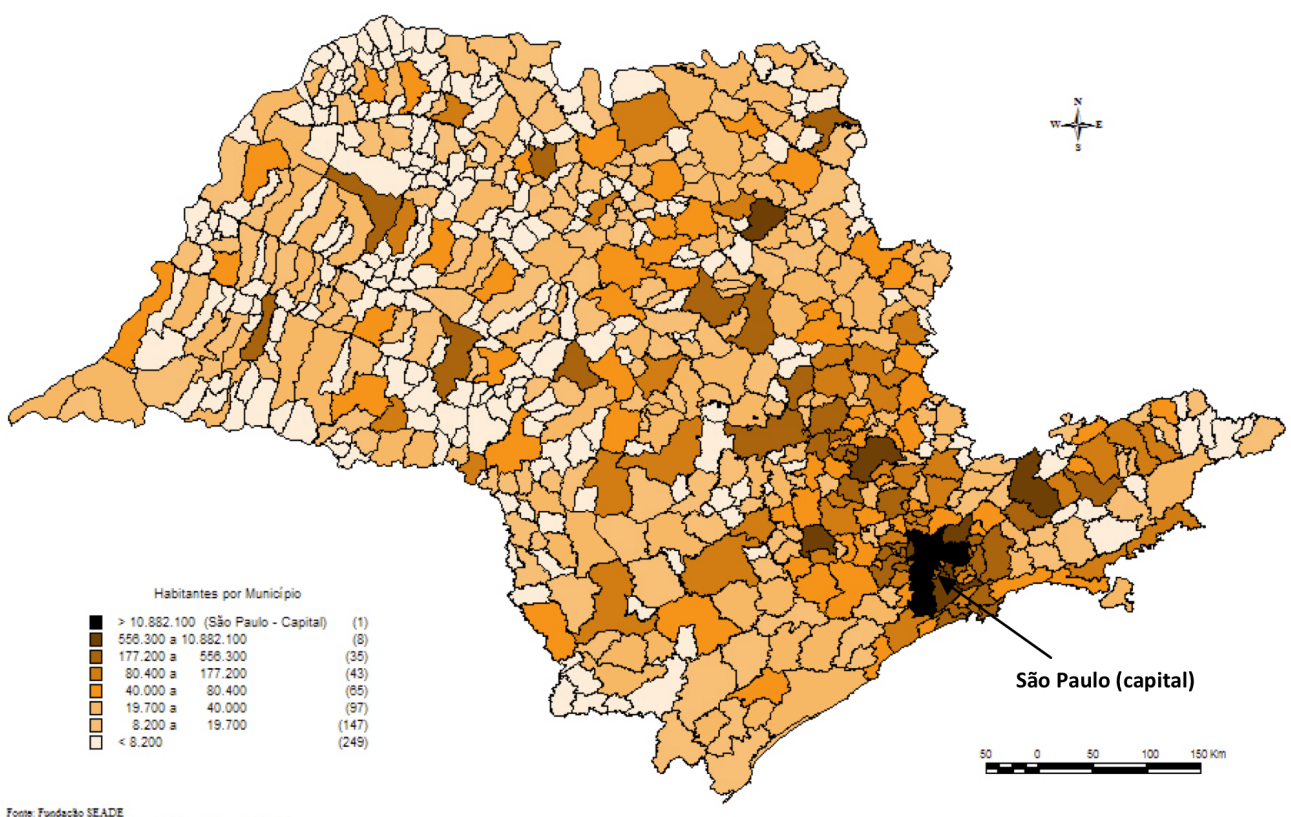

Tabela 1 - Investimentos para construção e reforma de prisões entre 1997 e 2006 e distância ( $\mathrm{km}$ ) dos municípios até a capital do estado (cidade de São Paulo)

\begin{tabular}{|c|c|c|c|}
\hline Municípios & $\begin{array}{l}\text { Distância da } \\
\text { capital (km) }\end{array}$ & $\begin{array}{l}\text { Investimento } \\
\text { (milhões) }\end{array}$ & $\begin{array}{l}\text { Percentual em } \\
\text { relação ao total } \\
\text { do período }\end{array}$ \\
\hline $\begin{array}{l}\text { Campinas, Caraguatatuba, Diadema, } \\
\text { Franco da Rocha, Guareí, Guarulhos, } \\
\text { Hortolândia, Iperó, Itapecerica da Serra, } \\
\text { Itapetininga, Jundiaí, Limeira, Mauá, } \\
\text { Mogi das Cruzes, Mogi Mirim, Osasco, } \\
\text { Potim, Rio Claro, São Bernardo do } \\
\text { Campo, São Vicente, Sumaré, Suzano, } \\
\text { Taubaté (25) }\end{array}$ & até 200 km & $\mathrm{R} \$ 224,4$ & $31,5 \%$ \\
\hline $\begin{array}{l}\text { Araraquara, Avaré, Casa Branca, Itaí, } \\
\text { Itirapina, Iaras, Mococa ( } 7 \text { ) }\end{array}$ & 200 a $300 \mathrm{~km}$ & $\mathrm{R} \$ 74,2$ & $10,5 \%$ \\
\hline $\begin{array}{l}\text { Álvaro de Carvalho, Assis, Avanhandava, } \\
\text { Balbinos, Bauru, Franca, Getulina, Jaú, } \\
\text { Lins, Marília, Paraguaçu Paulista, Pirajuí, } \\
\text { Reginópolis, Ribeirão Preto, São José do } \\
\text { Rio Preto, Serra Azul (16) }\end{array}$ & 300 a $500 \mathrm{~km}$ & $\mathrm{R} \$ 194,3$ & $27,3 \%$ \\
\hline $\begin{array}{l}\text { Andradina, Araçatuba, Birigui, Caiuá, } \\
\text { Dracena, Flórida Paulista, Irapuru, } \\
\text { Junqueirópolis, Lavínia, Lucélia, Marabá } \\
\text { Paulista, Martinópolis, Osvaldo Cruz, } \\
\text { Pracinha, Pacaembu, Presidente } \\
\text { Bernardes, Presidente Prudente, } \\
\text { Riolândia, Tupi Paulista, Valparaíso (20) }\end{array}$ & mais de $500 \mathrm{~km}$ & $\mathrm{R} \$ 218,1$ & $30,7 \%$ \\
\hline Total - 68 municípios & & R\$ 711 & $100 \%$ \\
\hline
\end{tabular}

Fonte: Tribunal de Contas do Estado de São Paulo (TCE). 
Em 1997, teve início a atual expansão do SPP para os municípios do interior do estado, principalmente em direção ao oeste. ${ }^{15}$ É nessa época que se configura uma das marcas desse sistema penitenciário: uma segregação socioespacial com dupla consequência: a mudança na vida dos municípios que recebem as prisões e um maior distanciamento entre os presos e sua família.

A Tabela 1 mostra que $31,5 \%$ do total dos investimentos para construção e reforma de prisões ocorreram em municípios localizados até $200 \mathrm{~km}$ da capital (o município de São Paulo). A maior parte desses recursos foi utilizada principalmente para construção de Centros de Detenção Provisória (CDP). Já $58 \%$ do total dos recursos foram investidos em unidades prisionais construídas a distâncias superiores a 300 km da capital. E cerca de 218 milhões de reais - ou $31 \%$ do total - foram investidos em municípios localizados a mais de $500 \mathrm{~km}$ da capital, na construção de penitenciárias (unidades prisionais para condenados).

É importante qualificar a natureza dos investimentos na expansão do SPP e sua lógica territorial. Desse modo, parte significativa dos investimentos, cerca de $31,5 \%$, ocorre em municípios localizados a até $200 \mathrm{~km}$ da capital do estado (caso de Campinas, Osasco, Taubaté e Hortolândia, por exemplo). E decorre da construção de Centros de Detenção Provisória (CDP), unidades para presos não condenados.

\footnotetext{
15 Segundo o Tribunal de Contas do estado de São Paulo, entre março e novembro de 1997, foram firmados os primeiros 19 contratos entre o governo do estado de São Paulo, via Secretaria de Administração Penitenciária, com empresas para a construção das novas penitenciárias estaduais no início da expansão do SPP em fins do século XX.
}

Já muitas Penitenciárias - unidades para cumprimento de pena - têm sido construídas a mais de $500 \mathrm{~km}$ da capital (caso de Dracena, Pracinha, Osvaldo Cruz e Reginópolis, por exemplo). ${ }^{16}$

Também é interessante notar a escolha feita por dois municípios específicos para a construção de Centros de Progressão Penitenciária (CPP), unidades para presos em semiliberdade, que podem ter autorização para saída para trabalho, por exemplo. No caso, Pacaembu (672 vagas e 935 presos em 2011) e Valparaíso (672 vagas e 918 presos) estão localizados a mais de 500 km da capital. O primeiro, com população total de 13,2 mil habitantes; o segundo, com cerca de 22,5 mil habitantes (Censo de 2010), são municípios que, por conta de sua demografia e localização, podem trazer dificuldades para os presos em regime semiaberto encontrarem trabalho, e retornarem ao convívio em liberdade com autonomia e possibilidade de se manterem sozinhos. Isso por conta dos estigmas que, regra geral, acompanham a vida carcerária dos indivíduos durante e depois da prisão. Estigma existente sobretudo no entorno imediato da prisão fenômeno chamado por Herzog-Evans (2009, p. 19) de perímetro sensível - e que é mais intenso quando o meio geográfico no qual se localiza a prisão tem uma menor densidade urbana. ${ }^{17}$

\footnotetext{
16 Uma condenação é suficiente para a transferência para uma penitenciária para início do cumprimento da pena privativa de liberdade. Entretanto, como a mesma pessoa pode responder a mais de um processo ao mesmo tempo, depois de transferido para uma unidade distante para cumprimento de pena, o preso pode continuar tendo que prestar depoimentos em sua comarca de origem, se responder a outros processos penais.

17 "La prison, ce lieu symbolique du conflit entre la société et ceux qui sont considérés comme des facteurs de troubles, est donc en général mal acceptée par son voisinage; elle perturbe
} 
Isolando os prisioneiros também pela distância física, ${ }^{18}$ separam-se as pessoas de sua família, problema que mobiliza determinados defensores dos direitos humanos a também buscar saídas tecnológicas para aproximá-las da família. ${ }^{19}$

Já o aumento nos gastos com saúde e educação, dos aluguéis e no preço dos imóveis são outras implicações da instalação das prisões em pequenos municípios do interior paulista, o que tem provocado indignação em muitos prefeitos por aumentar as dificuldades na gestão de seus municípios. ${ }^{20}$

Entretanto, pouco se sabe, no momento, sobre algumas das maiores implicações deste distanciamento da maioria das unidades prisionais da região metropolitana de São Paulo, e de outros centros urbanos de grande porte, para o funcionamento do próprio SJC. Cogita-se que algumas das consequências sejam também um aumento nos custos no deslocamento dos presos, $^{21}$ e gastos com escolta e ampliação

l'écosystème social environnant par son présence. J'ai dénommé périmètre sensible cette zone, plus ou moins étendue en fonction de la densité de l'urbanisation qui entoure la prison. Au sein de cette zone, l'ensemble des relations sociales est affecté par la présence de ce bâtiment stigmatisant" (HERZOG-EVANS, 2009, p. 19).

18 "[...] o atingimento do destino não depende mais do movimento físico propriamente dito" (TRIVINHO, 2005, p. 67).

19 "Famílias de presos poderão fazer visitas virtuais: Sistema de comunicação a distância objetiva beneficiar familiares que não podem se deslocar para a visita presencial" (Disponível em: <http://www.crimecongress2010.com.br/portal/sit e/familias-de-presos-poderao-fazer-visitasvirtuais/>. Acesso em: 3 jan. 2012).

20 "Prisões 'inflam' cidades no interior de SP" (Folha de S.Paulo, 4 dez. 2010).

21 As audiências devem ocorrer na comarca de origem do processo, o que implica em deslocamento dos prisioneiros com escolta da Polícia Militar a cada audiência dos processos que o indivíduo responde. da infraestrutura dos municípios para abrigarem as novas prisões.

\section{O uso de celulares nas prisões}

A prisão tem várias funções na sociedade atual, servindo tanto para uma nova forma de administração da miséria pelo Estado Penal, quanto sendo muito mais uma resposta à insegurança social do que uma forma de ação da justiça criminal (WACQUANT, 1998; 2001; 2007). Deste modo, uma das suas principais funções na atualidade é 0 isolamento (para neutralização) de certos sujeitos indesejáveis no mundo exterior, pois ela é uma instituição falida para recuperação do delinquente (BITENCOURT, 2001).

Por conta de que se vive hoje em um mundo que exige, cada vez mais, o acesso de todas as pessoas à informação constante e atualizada diariamente, o isolamento dos indivíduos submetidos à pena privativa de liberdade com a proibição de leituras de jornais ou uso de telefones passa a ser questionado por importantes autores como, por exemplo, o professor Nilo Batista da Universidade Federal do Rio de JaneiroUFRJ. ${ }^{22}$

É nesse debate do acesso do preso à informação (e comunicação) que se insere a questão do uso do telefone celular. Mesmo sendo agora proibido, o celular é usado indiscriminadamente na prisão, como prática clandestina, por um número cada vez mais

22 Batista, Nilo. Mídia e Sistema Penal no Capitalismo Tardio. São Paulo: Revista Brasileira de Ciências Criminais - Instituto Brasileiro de Ciências Criminais - número 47 - Editora Revista dos Tribunais: ano 12: março-abril de 2004. 
significativo de prisioneiros. ${ }^{23}$ Ao invés de uma discussão mais séria e abrangente sobre a questão, o governo federal responde com maior endurecimento na penalização pelo uso desse equipamento. ${ }^{24}$

Os argumentos contrários a seu uso nas prisões é que os celulares poderiam servir para comandar crimes fora delas. Segundo diretrizes de governo em diversos níveis (do estadual ao federal), as punições pelo porte dos celulares deveriam, portanto, coibir a comunicação entre lideranças de organizações criminosas com o exterior, ${ }^{25}$ já que os aparelhos poderiam ser utilizados para diversas finalidades: falar com advogados ou familiares, comandar práticas ilícitas ou clandestinas, articular motins ou rebeliões etc. ${ }^{26}$ É esse o discurso oficial apresentado

23 "No segundo semestre de 2006, a SAP apreendeu 1.506 celulares nos 35 estabelecimentos prisionais do Oeste Paulista [...] no mesmo período, foram apreendidas 70 armas e 11.126 porções de droga nesses presídios" (Diário da Região, São José do Rio Preto, 18 jan. 2008).

${ }^{24}$ Para tentar coibir a aquisição de celulares por parte dos detentos, em março de 2007 foi aprovada a Lei Federal n. 11.466, que, alterando o artigo 50 da Lei de Execução Penal, estabelece como falta grave a posse de aparelho celular ou de seus componentes no interior de unidade prisional (Fonte: Supremo Tribunal de Justiça. STJ).

25 "Esses líderes, protegidos e dispondo de 'massa de manobra', comandam com a máxima eficiência megarrebeliões e atentados, com métodos típicos do terrorismo, adotando um sincronismo de operações de espantosa precisão, porque podem contar, nos dias que correm, com esse novo aparelho de comunicação que é o telefone celular. A possibilidade de comunicação imediata com o mundo fora dos presídios aniquila o valor essencial da prisão, que é a neutralização do potencial criminoso do bandido preso" (A vantagem de estar preso. Editorial. O Estado de S.Paulo, São Paulo, 18 maio 2006).

26 "Gegê, Vida Loka e Guga Paca são ligados ao PCC e foram apontados como os responsáveis por um motim ocorrido anteontem na P2 de Venceslau, horas antes dos ataques. Os três se recusaram a mudar de suas celas, logo após revista. Houve confronto na prisão - que teve todos os vidros das celas quebrados - entre detentos e integrantes do GIR (Grupo de Intervenção Rápida), da SAP, que deram tiros de borracha e soltaram cães. Grampos telefônicos da Polícia Civil apontam que, após o tumulto, chefes do PCC deram ordem, via telefone para criminalizar o uso do telefone celular no interior das prisões. ${ }^{27}$

Entretanto, haveria poucos indivíduos que utilizariam o telefone para contato com organizações criminosas (os quais poderiam ser monitorados pelas autoridades), pois a maioria usaria o telefone para manter algum tipo de vínculo não criminoso com o restante da sociedade (BATISTA, 2003).

Apesar de ser motivo de controvérsias, e continuar a ser proibido o seu uso, a maior parte dos aparelhos celulares ingressa nas prisões com a conivência dos próprios funcionários. ${ }^{28}$ Independentemente do juízo jurídico ou moral sobre essa questão, a prática do uso dos telefones celulares promove articulações entre lugares distantes, derrubando a ideia do isolamento pelo uso da arquitetura penitenciária. É assim que as prisões tornamse contíguas ao exterior, conectadas através de redes de comunicação, e que tornam-se possíveis com as conexões geográficas. ${ }^{29}$

celular, para os ataques" (Após Ataque, 3 Chefes do PCC são isolados. Folha de S.Paulo, São Paulo, 8 fev. 2007, grifo nosso).

27 "O projeto de lei do senador César Borges (PRBA) que no ano passado tornou-se a Lei $11.466 / 2007$, prevê como falta disciplinar grave a utilização de telefone celular pelos presos. Nessa linha, tramita na Câmara o Projeto de Lei (PLS n. $137 / 2006)$, do ex-senador Rodolpho Tourinho, que determina a instalação de bloqueadores de celulares em penitenciárias" (Projetos tentam tirar as prisões do caos. Jornal do Senado Especial, ano XIV, n. 2.789/169, Brasília (DF), 22-27 abr. 2008).

28 Numa unidade prisional de segurança máxima, os visitantes (amigos e familiares) têm que se despir, agachar-se e passar por vistoria feita com detector de metais, além de guardar na entrada da prisão todos os seus objetos pessoais, o que dificulta enormemente a entrada de celulares nas unidades prisionais por meio dessas pessoas, sem a conivência dos funcionários.

29 "Segundo a Secretaria Estadual de Administração Penitenciária, aproximadamente 900 celulares são apreendidos por mês nos presídios paulistas. Para - Ministério Público, os telefones chegam às mãos dos criminosos por meio dos agentes penitenciários" (Ligações telefônicas aumentam suspeitas do Ministério Público. A Tribuna, Santos, 9 jan. 2008, grifo nosso). 
Assim, a prisão contemporânea pode controlar apenas a mobilidade física dos condenados, já que suas ações podem agora facilmente ultrapassar seus muros, se houver acesso a telefones celulares, por exemplo. É essa a realidade que também deve ser considerada na discussão sobre a localização das prisões, sobre as questões do isolamento e sobre a finalidade das penas na atualidade.

No interior das unidades prisionais, os celulares também podem servir à comunicação entre presos isolados em módulos separados (divisões internas). Essa nova forma de comunicação, com a moderna tecnologia eletrônica, incorpora-se a outras práticas de comunicação mais rudimentares, já utilizadas há tempos nas prisões paulistas como as asas-delta ${ }^{30}$ e as pipas. ${ }^{31}$ Mensagens codificadas também podem ser enviadas para fora por carta e até mesmo com a participação de advogados. Por meio de certas mensagens, os presos podem tornar-se solidários uns com os outros, rompendo o isolamento físico impsoto pela arquitetura prisional e em busca da execução de estratégias com diversos fins, lícitos ou não. ${ }^{32}$

\footnotetext{
${ }^{30}$ Asa-delta é o nome que os presos dão a um objeto com certa massa física (uma laranja, por exemplo), para vencer a resistência do ar, em cujo interior inserem uma mensagem; atirado pelas muralhas, o objeto é resgatado por outro companheiro, de outro módulo ou raio.

${ }^{31}$ Pipas são os recados enviados ao diretor e/ou a outros funcionários da unidade prisional. Quando um preso quer uma audiência para discutir sua situação processual ou pedir transferência ou trabalho, por exemplo, ele envia um desses recados por meio dos funcionários mais próximos como os agentes penitenciários do raio.

${ }^{32}$ É difícil precisar quando os primeiros celulares entraram nas prisões brasileiras. Uma hipótese de trabalho pode ser a consideração dos telefones celulares, por conta de seu barateamento e difusão pelo corpo social. Entretanto, já no começo dos anos 2000, já se sentia o problema do uso dos celulares por presos paulistas., como evidencia esta reportagem com entrevista ao Diretor do DeicSP: Em novembro de 2002, o delegado Godofredo Bittencourt, diretor do Departamento de Investigações sobre o Crime Organizado (Deic), já atribuía ao RDD a desarticulação do PCC. Sem
}

\section{O discurso tecnológico como tábua de salvação do isolamento penitenciário e a reprodução capitalista na modernização das prisões}

Várias soluções tecnológicas têm sido cogitadas para impedir o uso de celulares no interior das prisões. Busca-se uma solução técnica, quando a principal causa do problema é a falta de um novo projeto político e da clareza dos significados do isolamento na sociedade contemporânea.

Por outro lado, é inegável que a busca de soluções tecnológicas alimenta disputas e controvérsias políticas, explicitando conflitos entre os diversos níveis de governo (união, estados e municípios) e as empresas de telecomunicações. ${ }^{33} \mathrm{~A}$ instalação de bloqueadores de celular e o desligamento de torres de retransmissão do sinal dos aparelhos, um grande negócio na modernização prisional (envolvendo grandes somas de dinheiro e várias empresas), têm sido recorrentes no enfrentamento das crises que decorrem da articulação entre prisioneiros e organizações criminosas.

A solução tecnológica envolve adotar remédios sempre paliativos, como os

acesso a celulares, os líderes passaram a se comunicar por intermédio de suas mulheres $e$, devido a uma rede de intrigas e inveja, a estratégia teria quebrado a hegemonia entre os chefões e supostamente provocado a derrocada do grupo (Internos perigosos podem ter regime diferenciado. Jornal da Tarde, São Paulo, 23 jan. 2003. Disponível em: <http://www.jt.estadao.com.br/ editorias/2003/01/23/ger017.html>. Acesso em: 30 set. 2003).

33 "O ministro das Comunicações, Hélio Costa, disse na terça-feira que qualquer ação emergencial para bloquear os sinais de celulares nas áreas dos presídios deve ser tomada pelos governos estaduais, e não pelo governo federal ou pela Agência Nacional de Telecomunicações (Anatel). Ele aproveitou a discussão e sugeriu que as próprias empresas de telefonia se encarreguem de comprar e instalar esses equipamentos" (Bloqueio de celulares nos presídios é responsabilidade dos estados. O Estado de S.Paulo, São Paulo, 17 maio 2006). 
bloqueadores de celular. Com a obsolescência tecnológica, a modernização coloca em situação de atraso os bloqueadores de celular instalados nas prisões a cada inovação, pela criação de novos equipamentos e pelas novas frequências para transmissão do sinal, ${ }^{34}$ o que exige a aquisição de novos e melhorados aparelhos, mas que logo também serão superados.

\section{O próprio Ministério da Justiça} reconheceu a condição de obsolescência dos equipamentos bloqueadores que já foram instalados nas prisões brasileiras. ${ }^{35}$ Como a modernização é acelerada, na incessante busca das empresas por mais eficiência dos serviços, redução dos custos e ampliação do mercado consumidor, esse projeto de bloquear os sinais dos telefones celulares já nasce fadado ao fracasso. ${ }^{36} \mathrm{E}$ é discutível se

\begin{abstract}
${ }^{34}$ O sistema de telefonia móvel utiliza-se de faixas (freqüências) do espectro eletromagnético para transmissão dos dados na forma de energia. Os primeiros bloqueadores impediam a transmissão e/ou recepção do sinal por aparelhos que funcionavam nas freqüências de $850 \mathrm{MHZ}$ (antigas bandas A e B). Para os novos aparelhos, que vão até uma freqüência de $2100 \mathrm{MHZ}$, nas modernas tecnologias de transmissão chamadas GSM, não há bloqueio do sinal, o que exige uma modernização dos antigos sistemas bloqueadores.
\end{abstract}

35 "Com a entrada das redes GSM, as antenas de bloqueio voltadas à frequência de $800 \mathrm{MHz}$, das bandas A e B - tecnologias TDMA e CMDA - tinham de ser atualizadas para cobrir a frequência de $1.800 \mathrm{MHz}$ das redes GSM, demandando um novo investimento por parte dos governos estaduais" (Bloqueio de celulares em presídios do país é obsoleto, diz DEPEN. IDG Now, 15 maio 2006. Disponível em: <http://idgnow.uol.com.br>. Acesso em: 8 fev. 2009).

36 "Hoje, no Brasil, coexistem três tecnologias celulares diferentes - uma analógica, a AMPS (Advanced Mobile Phone Service) e duas digitais, a TDMA (Time Division Multiple Access) e a CDMA (Code Division Multiple Access). As tecnologias digitais vêm, gradativamente, substituindo a analógica, uma vez que apresentam vantagens como melhor aproveitamento do espectro, melhor gerenciamento de rede e uma vasta quantidade de serviços adicionais, inclusive acesso a dados e à internet. Tudo isso contribui para um melhor atendimento ao usuário e amplia as possibilidades de uso dos sistemas, com ganhos para as operadoras e conseqüente redução dos preços dos serviços" (PASTE - Perspectivas para Ampliação e as questões da justiça devem ser deixadas sob responsabilidade das empresas, que buscam principalmente mercado consumidor, por isso têm sempre uma ação deliberada, intencional, premeditada e parcial.

Há diversos conflitos que decorrem de distintos interesses político-econômicos relacionados aos sinais dos celulares nas prisões e em seu entorno. Por isso, especialistas esclarecem que o bloqueio do sinal dos celulares nas unidades prisionais, mesmo sendo um procedimento simples, torna-se difícil de ser posto em prática pela falta de entendimento dos responsáveis por sua realização - seriam as operadoras ou o próprio governo paulista?

A relação entre os governos e as empresas, desse ponto de vista, segue a mesma lógica concorrencial de troca de favores e interesses que ocorre entre os grandes grupos empresariais. Assim, uma consequência dessas práticas é que a justiça (e o Estado, certamente) passam a ficar reféns da voracidade das empresas e das lógicas do mercado. ${ }^{37}$

A polêmica também envolve 0 montante dos recursos aplicados na modernização das unidades prisionais, num

Modernização do Setor de Telecomunicações. Brasília, DF: Agência Nacional de Telecomunicações - Anatel, 2000, p. 78).

37 "O Ministério da Justiça defende a criação de um projeto de lei que obrigue as operadoras de celular a responder pelo bloqueio do sinal nas penitenciárias, mas a Anatel (Agência Nacional de Telecomunicações) divulgou na segunda-feira $(15 / 05)$ um comunicado em que afirma que nem a agência nem as operadoras têm a responsabilidade pelo sistema de bloqueio" (Bloqueio em presídio não é caro, diz professor da USP. IDG Now. Disponível em: <http://idgnow.uol.com.br>. Acesso em: 8 fev. 2009). 
país carente de investimentos em saúde, educação e moradia, como o Brasil. ${ }^{38}$

Outra contradição entre empresas e governo tem sido o desligamento das antenas de retransmissão do sinal aparelhos celulares no entorno da unidade prisional. Quando se desliga uma antena de retransmissão do celular, a área afetada chega a atingir um raio de vários quilômetros, o que pode afetar muitos moradores que residem na mesma região das unidades prisionais. Essa "saída tecnológica" foi discutida no ano de 2006, quando houve rebeliões nas unidades prisionais e ataques a policiais por movimentos supostamente articulados no interior das prisões paulistas. ${ }^{39}$

Como resposta aos apelos populares e da grande mídia, desligaram-se torres de retransmissão dos celulares em diversas unidades prisionais. Essa atitude decorreu da pressão exercida pelos governos e

38 "Assessores da Agência Nacional de Telecomunicações (Anatel) informaram há pouco que o custo de instalação de bloqueadores de celular nos 300 maiores presídios do País seria de $\mathrm{R} \$ 330$ milhões. Segundo a Anatel, o bloqueio de telefones móveis custa $\mathrm{R} \$ 100$ mil por faixa. Como há 11 faixas em operação no País, a despesa totalizaria R\$ 1,1 milhão por penitenciária. Essa instalação, explicaram, seria necessária pelo menos nos 300 maiores presídios do País - ou seja, um custo total de $R \$ 330$ milhões. O deputado Laerte Bessa (PMDB-DF) indagou quem pagaria esse custo. A deputada Rita Camata (PMDB-ES) opinou: "Hoje, quem está pagando é o povo" (Anatel: bloqueio de celular em presídio custaria R\$330 mi. Pasta Notícias da Câmara dos Deputados. Brasília, DF, 11 abr. 2007. Disponível em: <http://www.camara.gov.br>. Acesso em: 8 fev. 2009).

39 "Em 2006, a facção Primeiro Comando da Capital (PCC) fez a maior ofensiva contra o Estado da história do sistema penitenciário brasileiro. Em uma onda de violência coordenada por celulares de dentro das prisões, em poucas horas, os detentos organizaram rebeliões simultâneas, ataques e atentados contra agentes penitenciários, policiais, guardas municipais e um bombeiro" (Lembre como foram os ataques de 2006 do PCC. Portal Terra, 11 maio 2008.2 Disponível em: $<$ http://noticias.terra.com.br>. Acesso em: 8 fev. 2009). autoridades policiais, na tentativa de retomar o controle da situação, no momento posterior a crise desencadeada pelas rebeliões e pelos ataques. $^{40}$

O que estranha a urgência na tomada dessa medida é que o problema já era conhecido, no mínimo, antes da ocorrência das crises e das rebeliões. ${ }^{41}$

O desligamento das antenas de transmissão dos sinais para telefones celulares teve outras consequências, pois a aplicação dessa medida prejudicaria municípios de menor porte. A tentativa de isolamento das novas unidades prisionais teve implicações constitucionais, já que a lei garante acesso de todos às telecomunicações, independentemente do lugar onde vivam. ${ }^{42}$

40 "A Agência Nacional de Telecomunicações (Anatel) e as empresas de comunicação móvel iniciaram nesta manhã as ações destinadas a inibir a comunicação móvel nas Unidades Prisionais dos municípios de Avaré, Presidente Venceslau, Iaras, Araraquara, São Vicente e Franco da Rocha, todas em São Paulo. A inibição da comunicação, excepcional e temporária, será pelo prazo de 20 dias" (Atendida decisão judicial para inibir comunicação móvel em presídios. Brasília, DF: Assessoria de Imprensa da Anatel, 19 maio 2006).

${ }^{41} \mathrm{Em}$ julho de 2001, a Assessoria de Imprensa da Anatel divulgou a seguinte notícia: "Depois de mais de seis horas de reunião, que teve início às $8 \mathrm{~h} 30$ de hoje, na sede da Secretaria Estadual de Administração Penitenciária, em São Paulo, ficou decidido que começa dentro de 30 dias a realização de testes dos equipamentos que visam a inibir a comunicação de celulares em presídios" (Testes de bloqueio de celulares em presídios começam dentro de 30 dias. Brasília, DF: Assessoria de Imprensa da Anatel, 31 jul. 2001).

42 "Na avaliação de Guilhermo Ieno Costa, advogado especialista em telecomunicações, a hipótese de vetar o sinal nas regiões próximas aos presídios é inconstitucional. "A lei garante o acesso a telecomunicações a todo e qualquer brasileiro, independente da localização", aponta. "Mesmo os usuários que moram ao lado dos presídios têm esse direito de comunicação assegurado. Não haveria justificativa para privar os usuários nem reputar às operadoras a responsabilidade sobre um problema que o Estado não consegue controlar". De acordo com o especialista, a ordem para bloquear o sinal não poderia ser tomada 
Ainda em 2007, uma reportagem de O Estado de S.Paulo revelou não haver acordo para bloqueio dos celulares, pois os governadores da região Sudeste decidiram entregar ao Congresso Nacional um documento com várias propostas para se combater a violência em seus estados. Entre elas, havia aquela que obrigava as empresas de telefonia a bloquearem os sinais dos celulares nas prisões. ${ }^{43}$

Diante da rapidez da evolução tecnológica, antes mesmo de se ter chegado a um consenso político, o desligamento das antenas de celulares já se tornou um debate superado, pois já existem aparelhos que não precisam de antenas de retransmissão, captando o sinal diretamente dos satélites. Eles podem ser usados em qualquer região do território brasileiro inclusive, no mar territorial, até uma distância da costa de 500 milhas náuticas. ${ }^{44}$

Desse modo, a redução da questão prisional, apenas, para questões tecnológicas dificulta 0 debate acerca dos principais problemas existentes nas unidades prisionais. Alguns deles: as reais carências dos presos

arbitrariamente, deveria partir do judiciário ou da agência reguladora, no caso a Anatel" (SP estuda bloqueio de celulares em regiões próximas a presídios. IDG Now, 15 maio 2006. Disponível em: <http://idgnow.uol.com.br>. Acesso em: $8 \mathrm{fev}$. 2009).

43 "Na avaliação de Serra, é preciso fazer uma lei que obrigue as operadoras de telefonia a bloquearem o sinal dos aparelhos celulares nos presídios porque é mais difícil impedir a entrada desses aparelhos nas prisões. "É mais simples e mais econômico fazer o bloqueio, existe tecnologia pra isso e eu estou convencido de que as empresas podem fazer isso," disse. E argumentou: "As empresas de telecomunicações têm função social" porque são concessionárias de serviço público." Fonte: Governadores querem lei para bloquear celulares em prisões. Caderno Cidades. São Paulo: O Estado de São Paulo, 27/02/2007.

${ }^{44}$ Ver a descrição do aparelho Globalstar no próprio site do fabricante. Disponível em: <http://www.globalstar.inf.br/globalstar/page_112 7446955290.html>. Acesso em: 8 fev. 2009. (trabalho, saúde, educação), a formação de grupos criminosos pela convivência promíscua e a corrupção dos agentes penitenciários e dos advogados, ${ }^{45}$ além é claro das funções exercidas pela prisão como componente do sistema de justiça criminal brasileiro.

\section{Outra questão que merece ser}

tratada relaciona-se ao rompimento das relações familiares, como consequência do distanciamento das prisões dos locais de origem dos prisioneiros. Como grande parte dos prisioneiros é de família pobre, a distância entre os locais para cumprimento de pena e de residência das famílias pode prejudicar a convivência familiar e social, dificultando sua reintegração quando em liberdade e, até mesmo, promover o abandono familiar. ${ }^{46}$

Além das implicações da modernização dos sistemas técnicos da

45 "Embora não comente sobre valores dos celulares em presídios nem sobre denúncias de corrupção de agentes penitenciários para facilitar a entrada dos aparelhos em casas penais do Estado de São Paulo, a Secretaria de Administração Penitenciária (SAP) informa que todo o celular apreendido dá origem a uma apuração interna para descobrir em que circunstância o aparelho entrou na prisão. Para diminuir o problema, de acordo com a SAP, foram investidos $\mathrm{R} \$ 34$ milhões. Por mês, de acordo com a secretaria, são apreendidos quase 900 celulares em 143 presídios, média de sete por unidade. A secretaria investiu na aquisição de equipamentos de raio- $X$ e detectores de metais para tentar barrar a entrada de celulares dentro das prisões. Foram 67 aparelhos de raio- $x$ pequenos, que custaram $\mathrm{R} \$ 80$ mil cada, mais 111 de maior porte, que custaram R\$208 mil cada, além de 152 detectores de metal comprados por R\$ 43 mil" (SP Investe R\$ 34 mi para barrar celular em prisões. Portal Terra, 19 jan. 2008. Disponível em: <http://noticias.terra.com.br>. Acesso em: 8 fev. 2009.

46 Muitos presos não recebem visitas quando se encontram em penitenciárias distantes. O governo federal, por exemplo, está investindo num sistema de teleconferência para colocar em contato presos e seus familiares. Entretanto, para o estado de São Paulo não há notícias de projeto semelhante. Disponível em: <http://www.conjur.com.br/2010abr-24/familias-presos-outra-cidade-contamagora-visita-virtual>. Acesso em: 8 fev. 2009. 
telefonia móvel, e das mudanças que provoca no aparato prisional, há uma necessidade da prisão não ser tratada de forma isolada. É fundamental contextualizar seu funcionamento em relação às desigualdades socioespaciais, às possibilidades de acesso a justiça pelos acusados, por exemplo, para que não haja falsa percepção do problema prisional. Fato que seria reduzi-lo a um tamanho menor do que possui em realidade, visto como uma questão isolada de outras questões sociais.

Em busca de solução dos problemas da prisão, os atrativos da tecnologia e seu comércio volumoso são tratados como prioridades. Entretanto, torna-se cada vez mais urgente um debate maior sobre os significados da prisão no Brasil atual, e do lugar que ela ocupa na reprodução das desigualdades socioespaciais.

Dentro desse quadro social, talvez a maior das contradições envolvendo a prisão seja a escolha de seus muros como ortopedia equivocada, como afirmara Michel Foucault, para preparar os indivíduos em reclusão para uma vida em liberdade, um grande paradoxo que já dura quase 200 anos.

\section{Considerações finais}

As transformações do meio geográfico, por conta dos aportes da técnica, ciência e informação, modificam as realidades dos lugares, portanto do funcionamento do sistema de justiça criminal.

As prisões, como componentes cada vez mais presentes nas paisagens dos municípios do interior paulista, ligadas ao funcionamento da totalidade social, participam de processos da justiça e das desigualdades cujas origens encontram-se distantes dos lugares que as recebem.

\section{Considerando-se a organização} territorial do SPP, há uma racionalidade em seu planejamento que se opõe tanto à dinâmica da concentração dos usos do território pela população e pelas empresas paulistas (com maior densidade nas três regiões metropolitanas do estado), quanto aos municípios com maior criminalidade. Deste modo, a expansão e modernização das unidades prisionais decorre de outros interesses além das questões específicas da justiça penal.

A modernização do meio geográfico, pela formação do meio técnico, científico e informacional, e as possibilidades de conexão remota rompem com as escalas intermediárias de ação e, desconsiderando o entorno imediato, promovem articulações entre lugares distantes. Perde sentido, deste modo, as tentativas feitas para isolamento penitenciário em unidades construídas em regiões distantes, além das implicações negativas desse processo (para os presos, e para os próprios municípios que recebem as novas prisões).

É urgente, portanto, uma discussão mais abrangente e aprofundada sobre as escolhas políticas que privilegiam a pena privativa de liberdade como uma das penas mais aplicadas no presente. O que envolve uma discussão sobre os custos das novas prisões (sociais, econômicos, políticos), e que também exige considerar o fracasso humanístico deste tipo de pena na contemporaneidade.

Além do maior aprofundamento destas dentre outras questões tratadas neste 
texto, outras pesquisas também poderão ser desenvolvidas em futuro próximo como:

(1)Conhecer novas conexões
geográficas, além daquelas
promovidas pelo uso dos telefones
móveis, e as mudanças no espaço
geográfico e no funcionamento das
instituições públicas e privadas;
(2)Ampliar o entendimento da
questão justiça versus novas
tecnologias, com ênfase no
sistema de justiça criminal
brasileiro; as das dinâmicas
(3)Conhecer no território do
transformações docisais
espaciais locais, no
município e no entorno próximo,

provocadas pela instalação de unidades prisionais;

(4)Conhecer como tecnologias de ponta, como os satélites e as TICs, possibilitam novas racionalidades para justiça criminal como o monitoramento remoto de prisioneiros.

Espera-se que estas reflexões possam contribuir tanto para o desenvolvimento de novos estudos geográficos quanto promover maior conhecimento do sistema de justiça criminal brasileiro. E que esse conhecimento também concorra para que haja mais justiça socioespacial no Brasil.

\section{Referências bibliográficas}

BATISTA, N. Mídia e sistema penal no capitalismo tardio. Revista Brasileira de Ciências Criminais. São Paulo: Instituto Brasileiro de Ciências Criminais/Editora Revista dos Tribunais, ano 12 , n. 47 , p. 1-20, mar./abr, 2004.

BITENCOURT, C. R. Falência da pena de prisão: causas e alternativas. 2 . ed. São Paulo: Saraiva, 2001.

CALDEIRA, T. P. Cidade de muros: crime, segregação e cidadania em São Paulo. São Paulo: Editora 34/Edusp, 2000.

GARLAND, D. As contradições da "sociedade punitiva": o caso britânico. Revista de Sociologia e Política, Curitiba, n. 13, p. 59-80, nov. 1999.

. Punishment and Modern Society: a study in social theory. Chicago: The University of Chicago Press, 1990.

FOUCAULT, M. Vigiar e punir. 26. ed. Petrópolis: Vozes, 1987.

HERZOG-EVANS, M. La prison dans la ville. Toulouse: Érès, 2009.

MARCHETTI, A. M. La prison dans la cité. Paris: Desclée de Brower, 1996.
MELOSSI, D. ; PAVARINI, M. Cárcere e fábrica: los orígenes del sistema penitenciario. Siglos XVI-XIX. 2. ed. Espanha: Siglo XXI, 1985.

PAIXÃO, A. L. Recuperar ou punir? Como o Estado trata o criminoso. São Paulo: Cortez, 1987.

PERROT, M. Os excluídos da história: operários, mulheres e prisioneiros. 4. ed. São Paulo: Paz e Terra, 2006.

PORTO, R. Crime organizado e sistema prisional. São Paulo: Atlas, 2007.

RAMALHO, J. R. O mundo do crime: a ordem pelo avesso. Rio de Janeiro: Graal, 1983.

SANTOS, M. Técnica, espaço, tempo: globalização e meio técnico-científico-informacional. 5. ed. São Paulo: Edusp, 2008.

A natureza do espaço: técnica e tempo, razão e emoção. São Paulo: Edusp, 2002.

. Por uma outra globalização: do pensamento único à consciência universal. Rio de Janeiro: Record, 2000. 
La nature de I'espace. Paris: L'Harmattan, 1997.

\section{A metrópole corporativa e} fragmentada: o caso de São Paulo. São Paulo: Nobel/Secretaria de Estado da Cultura, 1990.

. Espaço e método. São Paulo: Nobel, 1985.

SOUZA, M. A. Conexões geográficas - um ensaio metodológico: uma versão ainda preliminar. Revista do IEA, São Paulo. p. 113-128, 1991.

TRIVINHO, E. A condição transpolítica da cibercultura. Revista Famecos, Porto Alegre, n. 31, p. 91-101, dez. 2006.

. Introdução à dromocracia cibercultural: contextualização sociodromológica da violência invisível da técnica e da civilização midiática avançada. Revista

Famecos, Porto Alegre, n. 28, p. 6378, dez. 2005.
WACQuANT, L. Punir os pobres: a nova gestão da miséria nos Estados Unidos [A onda punitiva]. 3. ed. rev. e ampl. Rio de Janeiro: Revan, 2007.

. As prisões da miséria. Rio de Janeiro: Jorge Zahar, 2001.

. L'ascension de l'état pénal en Amérique. Actes de la Recherche en Sciences Sociales, Paris: Collège de France, v. 124, sept. 1998a.

La tentation pénale en Europe. In: Actes de la Recherche en Sciences Sociales, Paris: Collège de France, v. 124 , sept. $1998 \mathrm{~b}$.

ZOMIGHANI JR., J. H. Território ativo e esquizofrênico: prisão e pena privativa de liberdade no estado de São Paulo. Dissertação (Mestrado em Geografia Humana) - Faculdade de Filosifia, Letras e Ciências Humanas, Universidade de São Paulo, São Paulo, 2009. 